\section{Overt yet unrecognized cyanosis in a 3-year old boy with right pulmonary artery-to-left atrium communication: malpractice or ignorance?}

\author{
NEVEN ČAČE • ALEKSANDAR OVUKA • IVA BILIĆ ČAČE \\ SRĐAN BANAC • VOJKO ROŽMANIĆ • VLADIMIR AHEL
}

NEVEN ČAČE $(\bowtie)$

Department of Pediatrics University Hospital of Rijeka Istarska 43.

51000 Rijeka, Croatia Phone: + +385 (0)51659143 Fax: + + 385 (0)51 623126 E-mail: ncace1@gmail.com

ALEKSANDAR OVUKA • IVA BILIĆ ČAČE •

SRĐAN BANAC • VOJKO ROŽMANIĆ • VLADIMIR AHEL University Hospital of Rijeka Istarska 43.

51000 Rijeka, Croatia

\begin{abstract}
We present the case of a 3 year-old boy with obvious and severe blue discoloration of the skin and mucous membranes, present since birth, accompanied by clubbing of the fingers. He lives in the city and has been seen regularly by his pediatrician, and yet was never recognized as cyanotic. Cardiac examination revealed a soft systolic heart murmur. Electrocardiography (ECG) and blood pressure were normal and all peripheral pulses were present. Laboratory tests showed arterial hypoxia and polycythaemia. Echocardiography (ECHO), Doppler, angiography and multi-slice computed tomography pulmonary angiogram were performed. A right pulmonary artery-to-left atrium communication was diagnosed. Other possible causes of cyanosis were excluded. The child underwent surgery. At follow-up, one year later, the child was in excellent health. Laboratory tests were within referent values and oxygen saturation was normal. Repeated ECHO studies showed a progressive decrease in the size of the left atrium. This case illustrates the importance of careful physical examination during everyday practice and emphasizes the importance of collaboration between the physician and parents to ensure child wellbeing.
\end{abstract}

Key words: cyanosis, clubbing, rightto- left shunt

\section{Introduction}

Cyanosis in children results from a variety of conditions, many of which are lifethreatening. The right pulmonary arteryto-left atrium communication was first reported by Friedlich and coauthors in 1950. (1) It is an extremely rare cause of central cyanosis in children. Other symptoms suggestive of the above mentioned anomaly are clubbing of fingers, exertional dyspnea, silent precordium, normally split second heart sound, nonspecific murmur over left or right auxiliary region. (1-4) The diagnosis is made by echocardiography and selective angiocardiography. Surgery or transcatheter closures are the definitive treatment modalities. $(5,6)$

\section{Case Report}

A 3-year old Caucasian boy living in an urban area was directed to our hospital for suspected cat scratch disease. On examination, extreme cyanosis of the skin and mucous membranes as well as finger clubbing were apparent. Personal history obtained from the boy's mother was astonishing: apparently the blue color of the skin was evident immediately after birth and had been present ever since. Apart from the fact that the skin would turn a deeper blue on crying or during upper respiratory tract infections, the mother stated that the child had always been in good health. He was regularly seen by his primary care pediatrician who never noted the blue discoloration of the skin. Cardiac examination revealed a soft systolic heart murmur, best heard at the right paravertebral region. Electrocardiography (ECG) and blood pressure were normal and all peripheral pulses were present. Laboratory tests showed arterial hypoxia (partial oxygen pressure $5.54 \mathrm{kPa}$ ) and polycythaemia (Erythrocytes $6.09 \times 10^{12}$, Hemoglobin 174 g/l, Hematocrit 0.50). Pulse oximetry saturation ranged from 78 to $82 \%$.

2M Echocardiography Doppler examination showed dilatation or a cistern behind the left atrium with normal pulmonary vein drainage, and chest $\mathrm{x}$-ray 


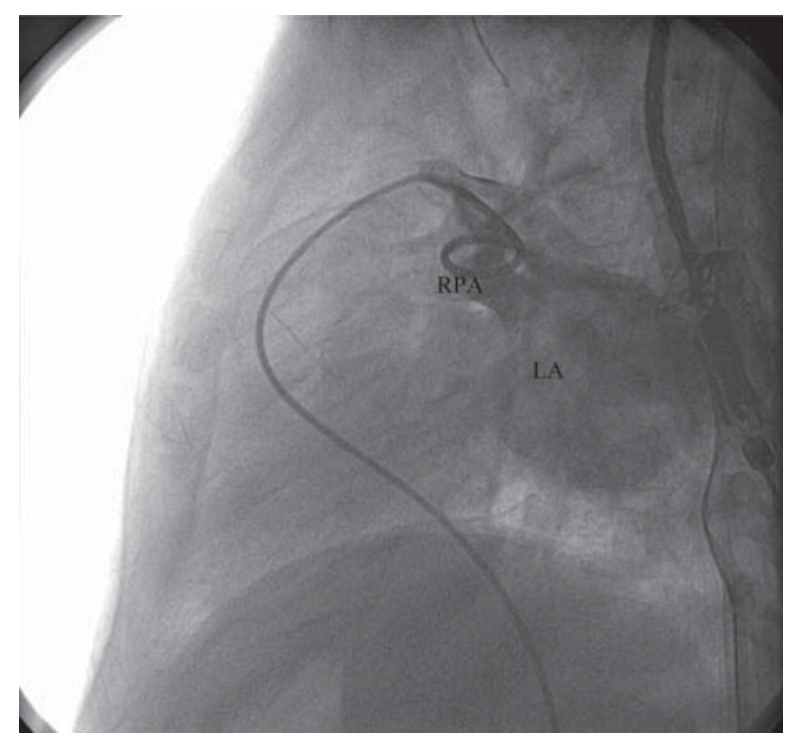

Figure 1. Lateral right arterial pulmonary (RPA) angiogram shows drainage to the left atrium (LA).

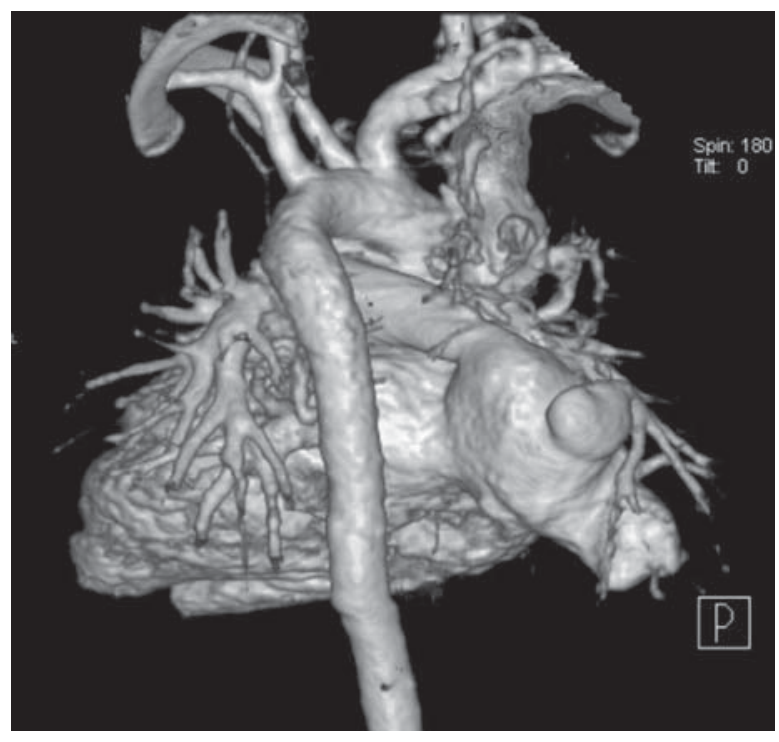

Figure 2. Multi-slice computed tomography (MSCT) pulmonary angiogram confirmed the aneurysm of the left atrium (ALA), $7.6 \mathrm{~cm}$ in largest diameter which was in wide communication with right pulmonary artery (RPA). revealed a posterior oval sac-like dilatation or aneurysm of the heart.

Angiography raised the suspicion that the inferior part of the right pulmonary artery could be connected by either a gigantic left atrial cistern, or the right pulmonary vein (figure 1 ).

A multi-slice computed tomography (MSCT) pulmonary angiogram confirmed the aneurysm of the left atrium and its wide communication (fistula) with the right pulmonary artery (figure 2).

Transcatether closure was not indicated due to the wide communication and so the child was directed to the Department of Cardiac surgery. During surgery, the right atrium appeared normal, a narrow persistent arterial duct was found and ligated, and the fistula was ligated and resected.

At follow-up, one year after surgery, the child was in excellent health. Laboratory tests were within referent values and oxygen saturation was normal. Repeated ECHO evaluations showed progressive decrease in the size of the left atrium.

\section{Disscusion}

A communication between the pulmonary artery and the left atrium is a rare congenital anomaly. (2) Symptoms depend on the magnitude of the rightto-left shunt, and consist of central cyanosis, clubbing of fingers, exertional dyspnea, silent precordium, normally split second heart sound, nonspecific murmur over left or right axillary region, and abnormal chest $\mathrm{x}$-ray findings. (1-4) The clinical diagnosis of right pulmonary artery to left atrium communications is rather challenging. Echocardiography and angiography provide necessary diagnostic information and define the anatomy of the anomaly. (5) Therapeutic options are surgery or in some cases transcatheter closure of the fistula. (6)

Unless the cause is known, episodes of central cyanosis require urgent assessment, especially in infants and young children, who require urgent hospital admission. (7) In our case, we were presented with a 3 year-old boy with obvious and severe blue discoloration of the skin and mucous membranes, present since birth, accompanied by clubbing of fingers. He resided in an urban area and was regularly checked by his pediatrician, and yet, never recognized as cyanotic or referred for further cardiologic and/or pulmologic work up. During our management of this case other possible causes of cyanosis (such as Rendu-Osler-Weber syndrome) were excluded. (7) Fortunatelly, long term hypoxemia in this boy did not cause any obvious neurological sequelae. (8) This case highlights the importance of careful physical examination during every day practice and emphasizes the importance of collaboration between the physician and parents to ensure well being of the child. 


\section{REFERENCES}

1. Friedlich A, Bing RJ, Blount Jr SG. Physiological studies in congenital heart disease IX. Circulatory dynamics in the anomalies of venous return to the heart including pulmonary arteriovenous fistula. Bull Johns Hopkins Hosp 1950;86:20-57.

2. Zeebregts CJ, Nijveld A, Lam J, van Oort AM, Lacquet LK. Surgical treatment of a fistula between the right pulmonary artery and the left atrium: presentation of two cases and review of literature. Eur J Cardiothorac Surg 1997;11:1056-61.

3. Alexi Meskishvili V, Dahnert I, Ovroutski S, Hetzer R. Right pulmonary artery-to-left atrium communication. Tex Heart Inst J 2001;28:120-4.

4. Saatvedt K, Stake G, Lindberg H. Fistula between the right pulmonary artery and left atrium—an unusual cause of cyanotic heart disease. Cardiol Young 1995;5:85-7.

5. Margaryan R, Arcieri L, Cantinotti M, Murzi B. Surgical closure of big pulmonary artery-left atrial fistula Interact. CardioVasc Thorac Surg 2010;10:113-4.

6. Slack MC, Jedeiken R, Jones JS. Transcatheter coil closure of a right pulmonary artery-to-left atrial fistula in an ill neonate. Cath Cardiovasc Interven 2000;50:330-3.

7. Allen HD, Phillips RP, Chan PD. History and Physical Examination. In: Hugh DA, Howard PG, Edward BC, David JD, editors. Moss and Adams Heart disease in infants, children and adolescents. 6th ed. Philadelphia: Lippincott Williams and Wilkins; 2001.

8. Perloff JK. The clinical recognition of congenital heart disease. 5th ed. Philadelphia: Saunders; 2003. 